\title{
REPRESENTATIVE DESIGN PRACTICES AS A DESIGNER'S RIGHT TO CREATIVE COMMUNICATION
}

Oksana M. Lahoda Doctor of Art History, Professor of Department of Design of Textiles and Clothes, Kharkiv State Academy of Design and Arts 8 Mystetstv Str., Kharkiv, Ukraine, 61002 https://orcid.org/0000-0003-1808-7119

oxanalahoda@gmail.com

\begin{abstract}
To be a designer means to create new things and new qualities of already existing things, determined by the current concepts. Information about the functions and emotional characteristics of the future product is initially reflected in the author's concept, that is, in the text about the qualities of a specific but not yet produced thing. This concept is consumeroriented but not intended for them. Nevertheless, it becomes the basis of communication between the designer, the product manufacturer, and the consumer. This study aims to determine how the process is organized, which ensures the transformation of the designer's creative ideas into conceptual texts and then into real objects that can become productive means of socio-cultural communication. The study relies on methodological foundations of a general philosophical nature. Thus, the axiological approach, as a socially holistic complex of views, beliefs, and ideals, allows a designer to analyze the values of a modern person and consider them in the design process. The phenomenological method reveals the features of design objects involved in communication. The structural and functional approach reveals the diversity and complexity of the connections inherent in the representation practices as original forms of communication. As the mechanisms of the representative practices are constantly developing, they are one of the most effective means for creative communication. By the results obtained, we can conclude that representations designed as a self-sufficient design product denote not only an act of such communication but also protect the designer's rights to express creativity at the interpersonal, professional, and social level of communication.
\end{abstract}

Keywords: design activities, forms of communication, the manifestation of creativity, representation.

\section{INTRODUCTION AND REVIEW OF LITERATURE}

Modern researchers insist that postmodernity formed the concept of design as an artisticdesign activity, oriented exclusively on the consumer (Kalvianen, 1999; Buchanan, 2001). The 
beginning of the 21st century marked the reorientation of a design towards individualizing the external shape of objects, remaining their technical content almost unchanged (Lahoda, 2018: 115-121). T. Bystrova (2017) argues that all design forms are artificial, therefore, cannot develop or change independently. This statement finds confirmation in all areas of design activity (Pedgley, 2007). Meanwhile, many researchers believe the transformation of one or another design form is possible due to filling it with different meanings and concepts (Degen, 2008). For contemporaries, this idea has become the main principle of creating a "variety" of design forms and was fixed at the international level (ICSID Papers, 2002).

By the way, David Harrison, in his book "A Century of Color in Design" (2020), determines color as an efficient factor of such "diversity" as it allows to demonstrate individuality with a color scheme within one form. As an example, the author takes the multicolored chairs by Charles Eames, developed back in 1950. Bruno Munari (2008), an Italian designer, used similar examples in his book "Design as Art," first published back in 1966. By analyzing his research and practical experience, the designer outlines the "boundaries" of design as the potential of a new field of artistic creation. With a similar argument, Vilém Flusser (2016) emphasizes that humans are „reflective and speculative beings.” Proceeding from above, humanity develops not only the culture but also its philosophy. Culture, in turn, appears before a person in the form of a constantly growing accumulation of things, in particular, design things. As Michael Press and Rachel Cooper (2008: 58-60) explain, designers are recognized as "cultural intermediaries" who create such qualities of design products that convey specific values, preferences, and consumption ideology to society. These qualities are due to the concepts of our time, for example, multifunctionality, environmental friendliness, or ergonomics. They determine the design forms that fill the human living environment and are a condition for their socio-cultural identification. The visual perception of separate objects and the environment, as the whole, along with the verbal message, makes this identification possible (Tomes et al., 1998). To put it differently, identification, in this case, is a consequence of verbal-visual communication (Lahoda, 2014).

Regarding the cultural self-definition in mass culture, one should remember that this culture transforms significantly in modern times (Baumeister, 1986). As Andrei Flier and Anna Kostina (2009) constitute, the mass culture of the late XX - early XXI century greatly differs from its form at the beginning of the XX century. On the one hand, modern mass culture retains the features of the early period but, on the other hand, transforms under the influence of changes manifested in cultural life (Krutous, 2005). The transformations affected such properties of mass culture, without which it was previously considered impossible to be described. Basic characteristics of mass culture do not longer involve the concepts of standardization, typification, unification, "indulging" low tastes, and opposition to the ideals of high culture. However, one of its determinative tendencies is the homogenization, i.e., homogeneity, which manifests itself, in particular, as a complex interaction, and sometimes a synthesis, of mass and elite cultures (Razlogov, 2005).

Naturally, all of the above influences design and its practices and determines the "coordinate system" of its development. Since the designers act consciously and understand what exactly they create and design, their subjective ideas and their creative world are subjects of scientific interests. Through the prism of this world, even the entire society becomes interested in 
such ideas. The designer's focus on the person, the pronounced anthropocentricity of his or her activities at all stages of the design process, without exception, oblige him or her to communicate. Thus, the ability to communicate with potential consumers stimulates the designer to explore their lifestyle, habits, standard behavior, significant emotional experiences, impressions, etc.

The consumption process becomes a way for most people to express their individuality, emotions, and hedonism since consumption can emphasize the differences from others and thus give a person pleasure. In addition, the determination and positioning of differences, in most cases, determine the status of an individual in society. Thus, a person can believe consumption to be a source of „freedom of choice” within the boundaries that regulate his or her life and fill it with meaning. Based on this choice, a culture of consumption is formed and developed. The researchers note that "consumer culture is a design impression that unites production with consumption, and a professional designer with a creative consumer" (Press and Cooper, 2008: 61). Creative consumption, like creative designing, provides conditions for meaning-making, stimulating creativity and its manifestations. In this context, the positioning of the design product, its presentation by the designer to potential consumers are of particular importance. This is a peculiar form of communication - a communicative act, defined by the author as representation. It is also a self-sufficient product of creativity, created and implemented by a designer while positioning the design product.

Language and communication play an important role in designing, first of all, as the design process is viewed as exclusively visual, creative thinking (Lahoda, 2018: 119). Press and Cooper (2008: 213) argue design is a negotiated social process that requires the same level of communication. That is the reason Halyna Lola (2011: 28) defines design as a communicative practice that creates an "impression situation." But what is this practice? What is its specificity? How does it manifest itself? These questions remain without substantiated answers but are marked by the generalizing property of conceptualization.

Thus, the purpose of this study is due to the need to determine how the design process must be organized to ensure the implementation of the designer's creative ideas through conceptual texts into real design objects. The study also aims to define the conditions under which such design objects can become means of socio-cultural communication and ensure its productivity.

\section{MATERIALS AND METHODS}

The study relies, first of all, on methodological foundations of a general philosophical nature. In particular, to analyze the person's values, which are taken into account in the design process, we have used an axiological approach. This approach should be understood as a socially integral complex of significant views, beliefs, and ideals inherent in a society of mass culture. A phenomenological method allowed analyzing the features of design objects related directly to communication in the field of design. Diverse material on the practices of presentations and representations in design served the basis for distinguishing common and distinctive features of existing formats, their key functions, tasks, and expected results. The structural and functional approach, applied to various formats of representations, revealed 
the diversity and complexity of the connections between them. The generalization of the results obtained allowed us to conclude that representative design practices are the original forms of communication between the designer, the manufacturer, and potential consumers. At the same time, they mean self-sufficient creative practices, which, like any other design product, are based on a creative idea, its conceptualization, and implementation by means of design.

Under the research, a descriptive method was also used as it met the set objectives. This method helped to reveal the consumers' attitude towards the concept of product design and its representations. The analysis of narratological strategies was correlated with consumers' awareness of how the practices of representation impact emotionally and psychologically on a particular consumer and consumer culture in general. The study aimed at examining the designer's creative potential, its protection in the socio-cultural environment, and its role in consumer preferences regarding representations as an act of communication.

The theoretical base and information support were the research of scientists and the practical work of designers who considered the problems of design theory, design processes, aesthetics, art, socio-cultural foundations for the formation of the representations, the spread of new products in the post-industrial consumer society. While analyzing, we determined the state of research and the scientific components of a material and cultural approach to the study of the trends in the development of the design. We characterized the research dedicated to design and carried out in the humanities, the key directions in recent decades, and how identification problems influence it. It has been established that an interdisciplinary approach plays an important role in the study of the practice of representations in design as systemic acts of creative communication. By main directions of research were substantiated: the chronology of the development of various formats of representations; basic prerequisites to form a system of representative practices in a society of mass culture and mass consumption.

The representative practices were explored using the example of fashion design in the fashion industry. However, we should note that with any other design product, they, in our opinion, would be identical, with a slight difference. Since the key functions of different representation formats are practically identical, it is possible to argue that their organization is the same. On this basis, sources for the study of representations were divided into several groups. The first group includes scientific developments in various humanitarian knowledge: philosophy, sociology, psychology, cultural studies, narratology, art history. The second comprises historical and up-to-day information about the designers' activities and fashion brands. It was obtained from official sources and the media: official websites, print publications, videos and Internet sources on professional guidance, Internet platforms for design project implementations, and designer brand formation in different segments of the fashion market. Of particular interest were the visual materials presented in exhibition catalogs, brochures, and other printed products of international projects and textile companies. Regarding socio-cultural identification, the functions of representation of fashionable suit design, the existing formats of such representations, we have analyzed several issues that require further in-depth research in the context of their importance for creative communication. 


\section{RESULTS AND DISCUSSION}

The results obtained allow us to consider representative practices as a creative activity of a designer, which is based on various formats for presenting a design product (in this case, a suit). Set representative principles and narrative strategies determine the means of presentation and the content of what is presented. We do not regard presentation as an elementary demonstration of a certain sample or model. However, it implies a complex of sequential actions, aimed, in addition to the visual demonstration, to convey diverse information about the figurative, stylistic, formal-constructive, and other characteristics of the object. These characteristics can evoke associations, emotions and form an attitude towards the object itself.

It has been established that in the historical and cultural context, two methods to position a suit as an external form of an identity narrative have developed, which are primarily associated with the means of communication. Conventionally, they can be divided into an artistic and graphic fixation and volumetric-spatial, i.e., visual demonstration. Both methods are the result of the visualization process. Though, the first method involves such means as display, rendition, stylization, or interpretation that give the image an expressive metaphoricity as in a work of art. In the second method, the means can be considered the exposition of really created things (suit complexes) as a component of the visible (visual) image.

Common to both methods is a set of functions that they perform, namely: share fashion trends; spread aesthetic norms, tastes, ideals; regulate according to social stratification; educate, inform, advertise and popularize; provide communication and entertain. At different times and under different socio-cultural conditions, different functions dominated, but they were always solved in a comprehensive manner and interaction. That helped to implement certain communicative and manipulative narrative strategies.

The mentioned methods of representing the suit gradually form the basis for the types of representative practices, which we have united into the following groups: print-run; spectacular (performance), which, in turn, are divided into dynamic spectacular and static spectacular; virtual, which can include synthetic (hybrid) practices of representation (traditional media - audio, television, and visual communications) and directly virtual (new media - digital, network technologies and communication). Within each type of representative practice of suit design, separate formats of representation are distinguished. They differ, first of all, in the means of implementation and functioning.

The following formats are referred to the print-run practice of suit design representation: fashion illustration - its artistic and technical types; fashion photography (photo illustration) - studio-production type (thematic, portrait) and documentary type; artistic photographic illustration of fashion as a subject-thematic or narrative-conceptual. Performance practices of suit design representations involve dynamic and static formats. The dynamic format should include fashion shows, which can be divided primarily into haute couture and prêtà-porter shows, as well as season, off-season, and thematic (or special) representations. All of them provide for the participation of models, who are suit demonstrators.

Representative practices of static performance format determine the use of mannequins as special demonstration equipment that imitates a person - the wearer of the suit and the 
renderer of basic narrative. The static format implies, for example, a showcase (showcase as a modern design activity), within which product, subject, and product-subject, closed, open, and closed-open showcases are distinguished. Another static performance format for the suit representation is its exposition in the museum space. Depending on the curatorial strategy and type of a particular museum, a suit can be represented in a historical, artistic, memorial, special (thematic), or virtual format. The content of the exposition can be historical and cultural, personalistic, thematic, conceptual, and narrative.

Virtual practices for suit design representation developed later and absorbed other forms of representation thanks to new technologies. Among them, in our opinion, one should distinguish between synthetic representations (traditional media) and directly virtual formats of representative practices (new media). Synthetic representations include fashion TV shows, TV shows as thematic programs, video shows, video reports, video magazines, videos, teasers, etc. One should mean by the virtual formats of practices for suit design representation, first of all, websites: copyright (of a designer or a separate brand); of specialized publications; thematic; blogger websites. Virtual formats of presentations should also include online shops, online publications on style and fashion, etc. Virtual fashion museums constitute the distinctive format of suit design representations.

The interrelationships of various forms of representative practices with each other indicate synthesis in some cases and others - absorption as an interaction. Each of the studied formats as a narrative strategy for presenting a design product implements the set principles of representation. We conventionally denote these principles as "a suit," "a suit on a person," and "a person in a suit." For example, the principles "a suit" and "a suit on a person" prevail in the fashion illustration. However, the principle "a person in a suit" has a priority in fashion photography. As visual narratives, various types and formats of representative practices have their inherent parameters and characteristics, determined, first of all, by such artistic design means as means of organizing the visual environment (genre-stylistic); means of enhancing emotional expressiveness (artistic and figurative); visual harmonization means (conceptual content). Their interaction can provide a single basic or metanarrative that a designer can implement, manifesting the image of a design product in any of the presentation formats. The narrative must be broader and more meaningful than the concept of product design; however, the narrative contains it. Therefore, we can interpret this concept in different contexts in terms of the meaning of representations.

For this research, it is essential to take into account that modern science of design considers it as a phenomenon, as a process, as a sphere of creative activity, and as its result - a design product. This allows studying design more broadly and gives multidimensional and interdisciplinary opportunities for its research. So the designer can get the information necessary for the work, the question of communication is present in each variant: surveys, testing, positioning, demonstration, etc. Such information is a priori objective-subjective, sufficient emotional, and always justified by one context or another - socio-cultural conditions, historical, political or economic events, a situation, social phenomena. In other words, information is always ambiguous, and the broader and fuller the communication, the more accurate and reliable the information received. 
For communication, designers often use the presentation as direct action - to show, demonstrate, tell. But they use representation as a creative act more actively - performance, exposition, video, show. A designer uses both presentation and representation as a reference point while developing and manufacturing a design product as well as presenting it to potential consumers. Advertising design for a particular product is also used for this purpose. Moreover, self-presentation is particularly important for the consumer while consuming the design product, its advertising, as one of the representation tools. It is realized through the acquisition and ownership of a design product, its use, which gives a person a certain status, confirmed by identification. Accordingly, representation is a form of visual communication.

Human perception of visual information in the course of representations remains a rather individual ability to "see" the world in images, interpreting them in the context of perception and transformation of meanings. People commonly describe what they see in words, verbally formulating their emotional impressions. A designer can use completely different, unique tools of professional language for this. They constitute so-called design tools. In addition, the designer uses legitimate and generally understandable signs, symbols, and their meanings, which become the discourse of design practice. In general, to convey generally accepted aesthetic ideals, stereotypes, and norms of behavior that form a single information space, designers use a professional language of form and style formation, symbols, which can be brands, trends, as well as samples of mass culture or everyday phenomena. This determines the essence of the representation practice as one of the forms of creative communication.

Representation as an action or a sequence of actions is a special process. This process has an informational and narrative character that allows defining it as a narrativization. Its result is a narrative, a story, in our case, about a design product, its functions, quality, special properties, and creator. The narrativization is commensurate with the process of broadcasting information, i.e., it represents a communication process. Its participants are the one who broadcasts the information (designer) and the one who perceives it (the consumer). The process of narrativization takes place in certain conditions or situations, determined by time and place (location). There is the most important fact: a specific goal determines its course, in which a certain attitude towards this process is formed. As a result, various strategies of narrativization build a narrative that, in the design of the representations themselves, develops and formalizes the creative idea of the designer as a creator.

Products of design creativity predetermine conceptual transformations through narratives - stories, addresses, quotations that, in general, ensure continuity in culture. The dynamic of such transformations is due to the uniqueness of the connotations created by the designer. This provides a continuous process of „renewal” of actual images, stylistic techniques, forms of design objects, and their advertising. It is in this context that the fundamental category of creativity takes on exceptional significance. First of all, we speak about the ratio of creativity of both designers: the one, who creates a specific product, and the one who represents this product as an actual (often fashionable) sample. We also should consider potential consumers of a "fashionable" product capable of creative self-expression, that is, self-presentation through the use of a particular design product. Thus, we can say that three processes, namely communication, representation, and narrativization, constitute „a coordinate system” of design creativity. Being independent and, actually, self-sufficient, 
these processes are at the same time closely interrelated, especially if one designer creates them.

Within such a coordinate system, design should be defined as a complex system where narratives appear, develop, interpret, transform, spread, are represent, and function. We can view their meaning from different perspectives. For example, we can consider them prosaically as a basic function of a thing, i.e., its immediate purpose. They can be regarded poetically through the prism of artistic and aesthetic qualities of a thing. They may be viewed from a journalistic perspective as an event report, documentation of a real-life moment. We can also consider the meaning of narratives from the following perspectives: fantastic (futuristic) - as a fictional idea of a design product, its possible or desired functions, attributing certain qualities; conceptual - by transforming the content of the narrative into things or phenomena that the design product is not (the laws of advertising apply here).

Since a specific design language allows the content (meaning) to be encoded/decoded, it is possible to speak about semiotics (sign, symbolism). The semiotic system of design is discursive, develops according to the context and communication, which determines the representation format. In this regard, content, a narrative, stands as a "living organism" capable of self-development and self-improvement. The system "communication representation - narrativization" must complement the basic concepts of modern design development. It involves recipients, reflecting the anthropocentricity of the design. It bases on the conceptualization of problematic issues. Thus, the design is also conceptual, i.e., ecological, ethical, psychological, motivational, emotional design. The above system is characterized by virtualization as a key trend in modern life, which means the complete living of individual moments in the imagination, in other words, virtually.

Considering the perception of things that are represented, we, first of all, focus on the following: emotional perception and experience; the subjectivity and the plurality of interpretations that originate from the individual characteristics of a person or a particular social group. In this context, one should bear in mind that "artistic" and "aesthetic" perceptions are not identical. In other words, a design product may have pronounced artistic qualities (or not) but be perceived differently from an aesthetic point of view. This corresponds to the modern understanding of the category of "aesthetic." It is believed that "beautiful" and "low" belong to "aesthetic." During the postmodern era, one of the modern trends aimed to aestheticize the "ugly" and "low" is relevant for both contemporary art and design creativity. As a category, factor, and evaluation criterion, "aesthetic" allows you to analyze all other qualities and properties of the product. It is nevertheless closely connected with the "artistic" and, accordingly, with the "image-bearing." Therefore, the image should be considered as a key moment that influences the formation of a narrative, its development within the framework of representations, and functioning in communicative practices. Halina Lola (2016), the modern Russian scientist, stated this provision in her methodology of semiotic discursive modeling of the design product.

A designer thinks in images and uses them as a guideline in the design process. Images are a means of conveying creative ideas in representation. Consumers perceive namely images that motivate them to buy and own a particular thing. Therefore, representations of all possible formats carry the greatest semantic, instrumental, procedural, and other meanings 
for both the designers and the consumers of their product. Representation is the key to communication and creative expression. Thus, modern design is a holistic system consisting of the following subsystems: developing and creating a thing, the activities of a designer (or a team of specialists headed by a designer), products of design. All subsystems are closely linked by communication, in which representations, developed and implemented in the processes of narrativization, prevail.

\section{CONCLUSIONS}

We believe several important aspects actualize the problem of creativity in representative practices of design. First, various formats of representative practices coexist under modern conditions, which differ significantly. Their heterogeneity is determined by technical and technological differences while maintaining common functional tasks. Each participant of representative practices, a form of creative communication, has its own "degree" of individualized creative rethinking of the key idea. This not only adds "variety" but also provides individualization, and sometimes personalization of the design product, as an extreme form of its possible individualization.

The research results make it possible to formulate several practical recommendations for designers to use in their activities. In particular:

- in the form and style formation of the practical implementation of design projects and the representation of their results, it is necessary to be guided by the harmonization of the conceptual-figurative expressiveness and the suit functional practicability as an expression of a certain narrative;

- one should consider the narrative of the suit as a construct, allowing the image to identify and translate both simple and complex semantic formations. Conventionally: simple semantic formations mean a purpose, clothing style, target group; complex lifestyle, social values, global problems, etc.;

- a designer should take into account that the narrative must be not only broader than the concept of the design product but also include it in the semantic field along with the theme - the function of the future design product.

This gives the possibility to present a design product in various representation formats, as narrative strategies, according to different principles and through various artistic, design, and technological means that determine the creativity of communication.

Representation as a specific communication system requires a designer to develop conceptual strategies for the integrated implementation of informative, commercial, and entertainment functions. It forms subject-object connections, activates the sociocode, in particular, vestimentary, as a marker of socially significant meanings. Visual communication act is based on figurative and informational transmission and is implemented at the conceptual and narrative level. Within the framework of representations, the visualized image does the following: transforms into a "representative" or "narrative" one, as a sign of content; transmits information about the functions and values of the design product to the consumer environment; visualizes the "cultural body" of the suit wearer, determining its representativeness as a quality. Being representative, the image of a suit is a social marker and 
a means of identification. The links between the dominant characteristic of representations and the general trends in contemporary art, design, visual sphere are shown, first of all, at the artistic and technological level of their implementation.

Regarding the narrative strategy of individualization and personification, the mass broadcast of fashion suit images contributes to their independent reproduction by the consumer, allows to stylize the appearance, organizing self-presentation space of various aesthetic qualities. Virtual presentation formats are determined by the designer's creative narrative, the cult of the lifestyle, and the suit style, whereas a suit reflects a wearer's sociocultural values and the external form of the identity narrative.

Based on this, a typology of representative suit design practices has been derived. Within its framework, suit design is a figurative and symbolic representation of socio-cultural changes in the visual narrative form.

Thus, having analyzed the state, development trends, and features of representative design practices in visual communication and information perception, we revealed new directions for scientific research. The suit and its artistic representation are a means of expressing the designer's creativity. This means that representative practices transfer a recipient's attention from one sphere to another, namely, from visual perception to conceptual-visual comprehension.

\section{REFERENCES}

Baumeister, R.F. (1986). Identity: Cultural Change and Struggle for Self. New York: Oxford University Press. Buchanan, R. (2001). Design Research and the New Learning. Design Issues, 17(4), 3-23.

Bystrova, T.V. (2017). Thing, Form, Style: An Introduction to Design Philosophy. Moscow, Yekaterynburh: Kabinetnyi vchenyi.

Degen, M. (2008). Sensing Cities: Regenerating public life in Barcelona end Manchester. London: Routledge. ICSID Papers (2002). 4, 8-14.

Kalvianen, M. (1999). Customer Taste as a Challenge in the Design Process. Proceedings of the third international conference, European Academy of Design. Sheffield University, 2, 78-102.

Krutovus, V.P. (2005). Cultural self-identification of humanity under globalization. Culture at the turn of XX

- XXI centuries. Globalization processes. Moscow: State Institute of Art, 294-309.

Lahoda, O. (2014). Representation as an act of communication correlated by a narrative building. Art and Culture. Minsk: VSU named after P.M. Masherov, 2 (14), 15-20.

Lahoda, O. (2018). Costume design. Representation practices: monograph. Cherkasy: Vydavets Tretiakov O.M.

Lahoda, O. (2018). Search for Uniqueness and Identification Using Fashion. Space and culture, 6 (4).

Lahoda, O. (2018). Representative practices of the Costume Modern. Scientific development and achievements. London: Published by Sciemcee Publishing, 3, 29-43.

Lola, H.N. (2011). Design code: a culture of creativity. St. Petersburg: Elmore.

Lola, H.N. (2016). Design code: a methodology for semiotic discourse modeling. St. Petersburg: IPK Beresta. Munari, B. (2008). Design as Art. Penguin.

Pedgley, O. (2007). Capturing and analysing own design activity. Design Studies, 28 (5), 463-483.

Press, M., Cooper, R. (2008). Power of Design: The Key to the Consumer's Heart. Minsk: Hrevtsov Publisher. Razlohov, K.E. (2005). Mass cultural - a universal paradigm of our time. Theoretical cultural studies.

Moscow: Akademichnyi proekt; Yekaterynburh: Dilova knyha; RIK, 304-311.

Tomes, A., Oates, C. \& Armstrong, P. (1998). Talking Design: Negotiating the Verbal-Visual Translation.

Design Studies, 19, 127-142.

Harrison, D. (2020). A Century of Color in Design. Thames and Hadson. 
Flier A.Ia., Kostina, A.V. (2009). Culture: between the slavery of custom, the slavery of status and the slavery of consumption. Bulletin of the Moscow State University of Culture and Arts, 4, 13-18.

Flusser, V. (2016). State of Things - a small philosophy of design. Ad Marginem. 